\title{
A Economia Solidária em Ciência da Informação: interrelações e atuações possíveis
}

\author{
Fabricio Foresti \\ Mestre; Universidade Federal de Santa Catarina, Florianópolis, SC, Brasil; \\ forestifabricio@gmail.com \\ Gregório Varvakis \\ Doutor; Universidade Federal de Santa Catarina, Florianópolis, SC, Brasil; \\ g.varvakis@ufsc.br \\ Angel Freddy Godoy Viera \\ Doutor; Universidade Federal de Santa Catarina, Florianópolis, SC, Brasil; \\ godoy@cin.ufsc.br \\ Elizete Vieira Vitorino \\ Doutora; Universidade Federal de Santa Catarina, Florianópolis, SC, Brasil; \\ elizete.vitorino@ufsc.br
}

\begin{abstract}
Resumo: A Economia Solidária é uma alternativa de produção e consumo para reduzir as desigualdades sociais, um movimento internacional que emerge com outros temas contemporâneos. A pesquisa bibliográfica exploratória objetiva verificar como o tema da Economia Solidária situa-se nos estudos realizados em Ciência da Informação, bem como explorar os pontos em comum entre a competência em informação e a Economia Solidária. Os resultados mostram que o tema da Economia Solidária ainda é uma novidade em Ciência da Informação, contudo, outros temas correlatos apresentam produção científica considerável, que explora o potencial da informação no contexto econômico-sustentável. Mostram que existe convergência entre os ideais e os princípios da competência em informação e da Economia Solidária. Conclui-se que os profissionais da informação podem atuar de muitas formas diante da Economia Solidária, destacadamente com trabalhos relacionados ao desenvolvimento de competência em informação e por meio da realização de mais pesquisas sobre o tema.
\end{abstract}

Palavras-chave: Ciência da Informação. Economia Solidária. Competência em Informação.

\section{Introdução}

Sustentabilidade e responsabilidade social são termos fundamentais na contemporaneidade. Já é sabido que o modelo econômico atual é insustentável em um planeta com recursos limitados. Organizações são pressionadas a não só observar e solucionar os problemas que surgem no exercício de suas atividades, 
como a poluição causada ao meio ambiente, mas também a destinar, adequadamente, os resíduos produzidos e a realizar reciclagem. Isso ocorre ao mesmo tempo em que os consumidores mostram-se cada vez mais preocupados com a origem dos produtos adquiridos e com o descarte adequado do lixo. Como em todos os contextos da sociedade atual, a informação é peça chave, inclusive para o ideal da sustentabilidade tornar-se realidade. E a Competência em Informação tem grande potencial colaborativo ao ligar-se, estreitamente, aos ideais emancipatórios relacionados.

Dentre as alternativas de consumo justo, solidário e sustentável, emerge o fenômeno social da Economia Solidária (ES), modelo econômico alternativo ao praticado na atualidade pelo capital. Segundo o portal do Ministério do Trabalho e Emprego (2014) a ES é “[...] um jeito diferente de produzir, vender, comprar e trocar o que é preciso [...]" para sobreviver, "sem explorar" as pessoas e "sem destruir" o meio ambiente, onde consumidores e produtores pensam "no bem de todos e no próprio bem". No Brasil, o Movimento Econômico Solidário (MES) ganhou força com as iniciativas dos catadores de materiais recicláveis - atores que representam modelo real de cidadania e organização, além de se constituírem vetores importantes para a conscientização social. Contudo, a ES vai além dos catadores de materiais recicláveis. Pequenos agricultores e empreendedores individuais desempenham papel de igual importância e são responsáveis, em grande parte, pelo crescimento e destaque do MES no Brasil e na América Latina.

A aliança entre a praxe econômica e a solidariedade e sustentabilidade ganha cada vez mais espaço ao redor do mundo entre diversos setores da sociedade civil organizada e mesmo entre empresários. No Brasil, o Centro de Estudos e Pesquisas em Economia Pública e Social realiza, em 2017, a VI Conferência Internacional de Pesquisa sobre Economia Social e Solidária (CENTRO DE ESTUDOS..., [2017). Outros eventos ${ }^{1}$ mostram que a ES não é fenômeno restrito à América Latina ou países menos desenvolvidos; ao contrário, trata-se de realidade entre as grandes nações do mundo. A ES está organizada globalmente e em nações mais desenvolvidas, as atividades 
cooperativas são amplamente disseminadas entre a população. O Brasil ocupa posição muito abaixo das grandes nações, como EUA e países membros da União Europeia, onde mais de $50 \%$ da população exerce alguma atividade cooperada, seja de consumo, crédito, habitação, entre outras. Apesar da pequena participação dos brasileiros em atividades cooperadas, esse número aumenta a cada ano. Segundo dados da Associação de Cooperativas das Américas (COOPERATIVAS DE LAS AMÉRICAS, c2015), em 2010, no Brasil, existiam "6.652 cooperativas", enquanto na Argentina existiam "12.970" e na Venezuela "102.568" cooperativas registradas.

Os profissionais da informação podem dirimir diferenças sociais por meio da atuação profissional (PERES, 2011) e é possível que a Ciência da Informação (CI) tenha soluções adequadas aos problemas ligados à informação em ES. Aproximar a CI do MES pela pesquisa e extensão, pela abertura das portas das unidades de informação (bibliotecas, arquivos e museus) e pela introdução de técnicas de gestão da informação nas organizações solidárias, seja para a gestão de arquivos, informação e conhecimento, pode contribuir de forma definitiva com a sustentabilidade e a redução das desigualdades sociais. Assim, o objetivo central do presente estudo é verificar como o tema da ES emerge nos estudos realizados até o momento em CI. Além disso, busca explorar o potencial colaborativo da Competência em Informação para a ES e identificar os pontos em comum entre as duas temáticas.

\section{Procedimentos metodológicos}

Para atingir os objetivos propostos foi realizada uma pesquisa bibliográfica exploratória, em duas bases de dados da área de CI, uma nacional e outra internacional: Base de Dados Referenciais de Artigos de Periódicos em Ciência da Informação (BRAPCI) e Library and Information Science Abstracts (LISA). Também foi realizada pesquisa na base Scopus, para recuperar documentos da grande área de Ciências Sociais. O termo central utilizado na pesquisa foi "economia solidária", mas também foram aplicados termos associados como 
"economia criativa", "sustentabilidade" e "desenvolvimento sustentável". A busca se deu no título de artigos publicados entre o período de 2012-2016.

Para realizar a aproximação proposta nos objetivos, é preciso compreender não só o contexto da ES, sua importância na sociedade atual, bem como o olhar da CI e o discurso da Competência Informacional, para, então, verificar as ligações e as convergências entre as temáticas, além das formas de atuação possíveis da CI no MES. Para tanto, nas seções 3 e 4 é apresentada uma breve explanação sobre a informação e a ES, seguido pelos resultados da pesquisa na seção 5, em que é realizada a aproximação entre CI e ES. Na seção 6, o tema da Competência em Informação é explorado como alternativa de ação da CI na ES.

\section{Para entender a Economia Solidária}

Na ES, a economia é revista e orientada para objetivos sociais e melhoria da qualidade de vida dos envolvidos. (FRANÇA FILHO, 2004). A gestão nas organizações solidárias é especial por se tratar de empreendimentos constituintes de uma economia diferente, ou, mesmo, de uma nova dimensão da economia, onde não se distinguem usuários e fornecedores, cuja gestão organizacional apresenta dinâmica criadora de identidade. (ANDION, 2005). Desse modo, a informação que circula na ES tem grande importância social, é formadora de identidade e vetor de transformação social. Por conseguinte, é preciso compreender o fluxo da informação solidária.

Em que consiste a ES? Ela é definida pela Portaria n. 2060/2014 (BRASIL, 2015) do Ministério do Trabalho e Emprego como atividades econômicas desenvolvidas coletivamente por trabalhadores na forma de autogestão. A Portaria também define Comércio Justo e Solidário como formas de comércio "diferenciadas, pautadas nos valores de justiça social e da solidariedade" desenvolvidas pelos Empreendimentos Econômicos Solidários (EES). Essa Portaria representa importante marco ao MES, por estabelecer "princípios", "critérios" e meios de avaliar o exercício do "comércio justo e solidário" e a administração e a ordem do "Sistema Nacional de Comércio Justo e Solidário SCJS". Segundo o Ministério do Trabalho e Emprego (2014), a ES caracteriza- 
se pela cooperação, autogestão, dimensão econômica e solidariedade, movimento que reverte a lógica tradicional do capital ao não compactuar com a exploração dos trabalhadores, do trabalho e dos recursos naturais, ao observar o "ser humano na sua integralidade" e entendê-lo como "sujeito e finalidade da atividade econômica".

A atuação e impacto da ES ficam mais evidentes através dos Empreendimentos Econômicos Solidários - EES. O Sistema Nacional de Informações em Economia Solidária (SIES) define EES como organizações coletivas, muitas vezes sem registro oficial, que produzem bens e prestam serviços de comércio ou consumo solidário (por exemplo, as cooperativas). Também, incluem as entidades de apoio aos EES, como as organizações públicas ou privadas sem fins lucrativos, com iniciativas no apoio direto como treinamento, educação, consultoria, assistência técnica e gestão. (KUYVEN; KAPPES, 2013). A Portaria n. 2060/2014 (BRASIL, 2015) define EES como organizações associativas que exercem de forma democrática a gestão e a divisão dos resultados. Segundo Singer (2004, p. 8), os EES defendem o "meio ambiente" e o "bem-estar dos consumidores", são contra "tecnologias que podem ameaçar a biodiversidade, a saúde do consumidor e/ou a autonomia dos produtores associados e individuais". As associações voluntárias ou os EES têm a finalidade de prover aos participantes vantagens econômicas e emergem como reação às carências que o modelo capitalista atual não soluciona. (SINGER, 2001). Os EES são em grande parte constituídos por cooperativas, que sintetizam a essência da ES:

\footnotetext{
Cooperativa é uma associação autônoma de pessoas unidas voluntariamente para satisfazer suas necessidades econômicas, sociais e culturais comuns e aspirações através de uma empresa de propriedade comum e democraticamente gerida. [...] baseiam-se nos valores de autoajuda, auto-responsabilidade, democracia, igualdade, equidade e solidariedade. Na tradição dos seus fundadores, os membros das cooperativas acreditam nos valores éticos da honestidade, transparência, responsabilidade social e preocupação com os outros. (INTERNATIONAL CO-OPERATIVE ALLIANCE, 2015). (tradução nossa).
} 
As cooperativas são agentes importantes do desenvolvimento sustentável. A Aliança Cooperativa Internacional (INTERNATIONAL CO-OPERATIVE ALLIANCE, 2015) posiciona as cooperativas como "construtores da sustentabilidade" no projeto cooperativo global Blueprint, que criou agenda estratégica que, entre outros objetivos, espera até o ano de 2020 tornar as cooperativas líderes reconhecidos na "sustentabilidade econômica, social e ambiental". Tal qual a ES, busca unir a praxe econômica à "solidariedade", sustentadas no "trabalho associativo e autogestionário", de "propriedade coletiva", no "respeito ao meio ambiente e às diversidades", na "distribuição de riqueza e desenvolvimento local e sustentável" explicam Kuyven e Kappes (2013, p. 8).

No Brasil, o MES desenvolveu-se por meio das instituições governamentais, entidades de apoio, iniciativas comunitárias e associativas, cooperativas populares, redes de produção e comércio, feiras, entre outras. Atualmente, o movimento organiza-se em fóruns regionais e nacionais, com destaque para o Fórum Brasileiro de Economia Solidária (FBES) (FÓRUM..., 2014). Dentre as muitas iniciativas oriundas dos eventos relacionados, destacase a criação, em 2003, da Secretaria Nacional de Economia Solidária (SNES), para fortalecer o MES por meio de políticas públicas de trabalho e inclusão social (KUYVEN; KAPPES, 2013).

Após o entendimento do que consiste a ES, a seção a seguir busca esclarecer o sentido da informação em ES e apontar o fluxo da informação correlato.

\section{0 fluxo da informação solidária}

O caráter social da CI faz que ela se aproxime naturalmente da ES. O tema da Sociedade da Informação e do Conhecimento, tão discutido em CI, também está diretamente ligado à ES. Existe uma "parceria natural" entre a sociedade da informação e o desenvolvimento sustentável, reconhece Furnival (2000, p. 73). Durigan e Moreno (2013, p. 90) também reconhecem que: 
[...] vive-se em uma sociedade da informação, onde surgiram novos paradigmas na criação de novos rumos para o desenvolvimento, produtividade e qualidade de conhecimentos que nos habilitam a enfrentar as mudanças sociais com uma nova postura.

De fato, a informação facilita a construção das práticas de cidadania, fundamental ao sucesso das ações de organização social, afinal, é por meio da troca de informação que os atores sociais comunicam-se e conhecem direitos e deveres. Somente quando os indivíduos são capacitados a usar informação é que têm condições de participar politicamente da vida em sociedade. (BORGES; SILVA, 2006). Todavia, ao mesmo tempo, a informação é “[...] em si ambivalente, tanto em quem a pronuncia, quanto em quem a recebe [...] passa pelo filtro da subjetividade [...]”, segundo Demo (2000, p. 41), e encontra seus limites na percepção humana. Ainda assim, segundo o autor, é justamente a ambivalência da informação que abre espaço para a criação e a invenção.

O que é informação para a ES? A informação para o desenvolvimento sustentável é definida por Furnival (2000, p. 79) como um tipo de informação que "[...] se caracteriza pela $[\ldots]$ abrangência e natureza interdisciplinar, e principalmente pela $[\ldots]$ capacidade" de fazer emergir análises críticas que se revertam em "ação". Segundo a autora, a participação "ativa" das pessoas na "construção e representação da realidade" tem especial importância, ao se observar o papel que a informação pode desempenhar no processo de desenvolvimento. Como a essência da ES é o consumo solidário (KUYVEN; KAPPES, 2013) a informação para a ES ou a 'informação solidária' pode ser definida como àquela informação que promove o consumo solidário, que fomenta as atividades econômicas solidárias e valoriza as pessoas e o meio ambiente. 
Figura 1 - O fluxo da informação solidária

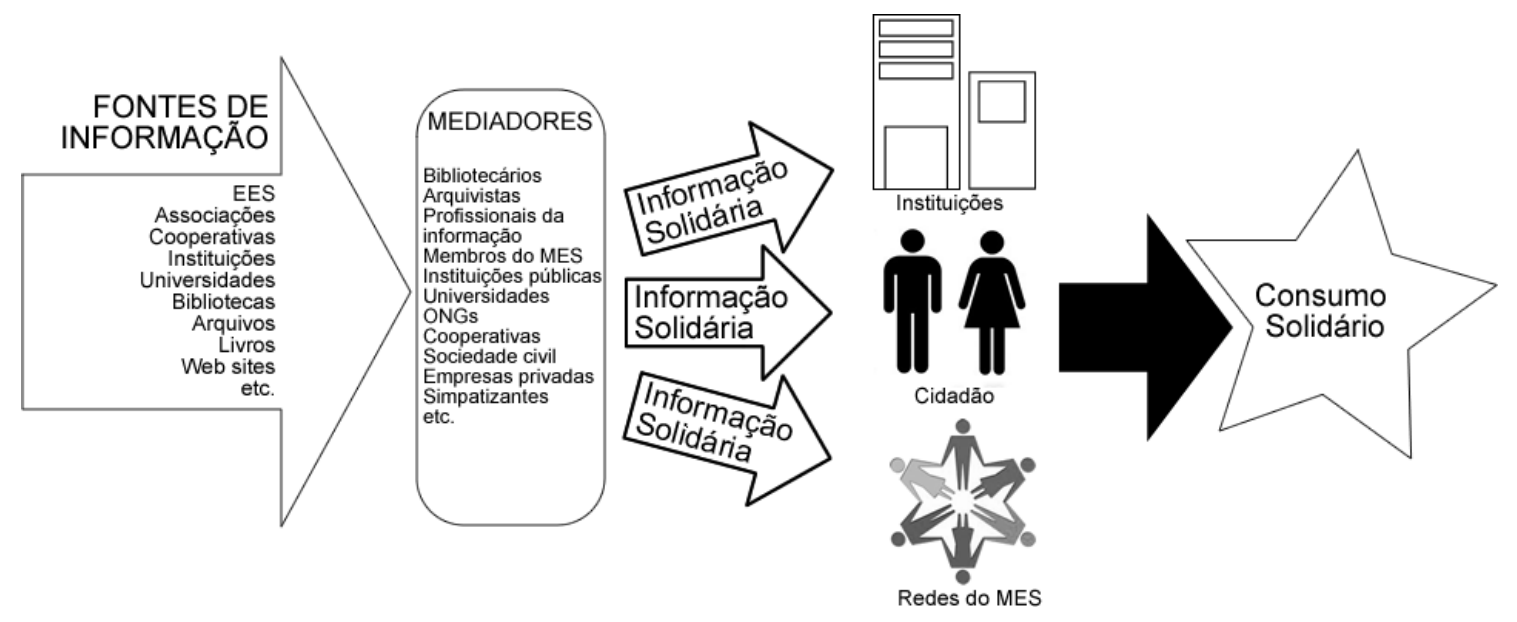

Fonte: Elaborada pelos autores.

Tendo em vista a definição de informação solidária, é possível explorar um fluxo da informação solidária. Em CI, estudar os fluxos de informação é entender as forças que os orientam e os interesses econômicos envolvidos na dinâmica da informação em rede - dinâmica que exprime intenções de mundos possíveis, de interação orientada à práxis, seja enquanto fonte ou receptor de informação. (SUGAHARA; VERGUEIRO, 2013). O fluxo da informação solidária deve proporcionar ao cidadão a tomada de consciência sobre o impacto social e econômico do consumo individual, e isto pode orientar ações de consumo mais conscientes e ao consumo solidário que, teoricamente, é uma ação que teria origem na informação solidária. O uso da informação, afinal de contas, "consiste na seleção e processamento de informações" e implica "novos conhecimentos ou ações", reconhecem Durigan e Moreno (2013, p. 102). A finalidade do fluxo da informação solidária, conforme ilustra a Figura 1, da mesma forma que a própria ES, é o consumo solidário (uma ação social). O entendimento desse fluxo solidário pode contribuir com a formação de cidadãos e instituições mais inteligentes, além de promover uma sociedade e economia mais justa e menos desigual.

Após o entendimento do que consiste informação e da identificação do fluxo da informação solidária, serão apresentados os resultados da pesquisa bibliográfica, para compor a aproximação entre a ES e a CI. O que dizem os 
autores da CI em relação aos temas associados? A ES é tema de pesquisa recorrente em CI? A CI já despertou para esta grande responsabilidade social e econômica? As pesquisas são convergentes com os ideais da ES? A seção seguinte busca responder essas questões.

\section{A Economia Solidária em Ciência da Informação}

A seção busca mostrar o panorama da pesquisa realizada sobre ES na grande área de Ciências Sociais e em CI. A pesquisa realizada na Scopus revela o cenário em Ciências Sociais que recuperou 24 artigos publicados entre 20122016. Dentre os temas contidos nos títulos emergem termos como conhecimento, informação, governança, políticas, solidariedade, público, trabalho da mulher, oportunidades, práticas, popular, cooperativo, mudança, cidadania, gestão, desenvolvimento, ecologia, iniciativas, inovação, entre outros.

Em CI o cenário é diferente. A pesquisa realizada na BRAPCI mostra que o tema da ES não é objeto de pesquisa entre os pesquisadores da área de CI no Brasil. Infelizmente, o tema se revela como novidade até o momento. Na LISA, não foram recuperados artigos, em conformidade com as especificações de busca apontadas nos procedimentos metodológicos. Em contrapartida, na BRAPCI, emergem os temas associados a ES com produção científica prolífica: "desenvolvimento sustentável", "sustentabilidade" e "economia criativa". Os autores da área de CI, no Brasil, que se destacam nos temas associados são Albagli (2009), Albagli e Pires (2012) Freire (2014) e Fonseca e Machado (2011).

Tabela 1 - Artigos recuperados na pesquisa bibliográfica

\begin{tabular}{r|c|c|c|c} 
& $\begin{array}{c}\text { Economia } \\
\text { solidária }\end{array}$ & $\begin{array}{c}\text { Economia } \\
\text { criativa }\end{array}$ & Sustentabilidade & $\begin{array}{c}\text { Desenvolvimento } \\
\text { sustentável }\end{array}$ \\
\hline SCOPUS & 24 & 68 & 3720 & 1331 \\
\hline LISA & 0 & 3 & 235 & 21
\end{tabular}

Fonte: Elaborada pelos autores. 
O artigo de Fonseca e Machado (2011) destaca-se na BRAPCI como o único artigo que apresenta o termo "Economia Solidária" no título. O uso da internet, benefícios e limites nos EES foi objeto de estudo de Fonseca e Machado (2011, p. 196-197), que apontam a ES como um setor "à margem do circuito da informação", mas com potencial de ampliar ações por meio da rede e das suas causas e seus ideais. Segundo os autores, as cooperativas e associações solidárias "experimentam a Internet como um meio para a prática" da ES. As iniciativas em ES tem a rede como ferramenta de grande valor, mesmo que o acesso ainda não seja realidade para grande parte dos envolvidos, o que deve mudar ao longo do tempo em função da inclusão digital. O Projeto Cirandas (CIRANDAS, 2014) criou a Rede Social da ES que coloca em comunicação direta os diversos atores envolvidos.

\footnotetext{
$\mathrm{Na}$ estrutura social em rede, a interação para troca de informação baseia-se em valores, confiança e interesses comuns. Nesta visão, acredita-se que a informação é entretecida, com seu uso nos espaços de convivência e dentro do feixe das relações sociais criando condições favoráveis para que as pessoas pratiquem solidariedade e participem da construção coletiva de conhecimentos. (SUGAHARA; VERGUEIRO, 2013, p. 94).
}

$\mathrm{Na}$ Scopus, foram recuperados outros documentos. Um estudo anterior (GODOY VIERA; FORESTI, 2016) mostra como a informação e temas relacionados são problematizados pelos autores da área de ES e aponta a necessidade do conhecimento da CI em benefício da ES. Segundo Godoy Viera e Foresti (2016), muitos artigos sobre ES apontam problemas relacionados à informação e às carências associadas, tais como: "produção", "fontes", “disseminação", “acesso", "aquisição", "tecnologia", "gestão", entre outras. Segundo os autores, são muitos os "tipos de informação" de valor para a ES, “[...] desde a informação sobre os EES até a informação comportamental, arquivística, administrativa, sobre produtos e serviços, [...] mas destaca-se a informação para a tomada de decisão coletiva e democrática." (GODOY VIERA; FORESTI, 2016, p. 41). 


\begin{abstract}
Os resultados mostram a preocupação dos autores que publicam sobre ES com as atividades ligadas à gestão da informação e do conhecimento, em especial o acesso, a disseminação e a produção da informação. Também revelam uma oportunidade para a Ciência da Informação propor soluções através do seu conhecimento, para facilitar o acesso e a disseminação da informação em todas as dimensões do movimento econômico solidário. As necessidades de informação apontadas pelos autores são básicas e estão intrinsecamente ligadas à educação e ao desenvolvimento de competência em informação. (GODOY VIERA; FORESTI, 2016, p. 39).
\end{abstract}

Existem, ainda, outras abordagens relacionadas à ES em CI. Os limites sociais e ambientais do sistema produtivo atual fizeram surgir na agenda internacional o desenvolvimento sustentável - tipo de desenvolvimento que exige novas abordagens para velhos e novos problemas. Neste contexto, a produção e o acesso à informação, ao conhecimento científico e popular, são fundamentais (ALBAGLI, 2009). A cooperação entre grupos e organizações, via bases de conhecimento sobre formas alternativas de desenvolvimento, são desafios ao desenvolvimento sustentável, necessitam de outra ética entre as nações, em que o acesso ao conhecimento e a informação, tal qual a diversidade cultural, precisam ser entendidos como fundamentais (ALBAGLI, 2009). Os novos fluxos de informação aumentam a importância do conhecimento tácito e do letramento, ou seja, da capacidade de contextualizar, interpretar e usar informação de formas novas. (ALBAGLI, 2009).

A Economia Criativa (EC) é outro tema associado à ES. Segundo Albagli e Pires (2012), o conceito de EC emerge nos anos 1990 e designa organizações que "[...] têm na arte, na cultura, na criatividade, no saber vivo e diário, na cotidianidade o seu processo produtivo e seu produto final, ao mesmo tempo." (ALBAGLI; PIRES, 2012, p. 112). Segundo os autores, o conceito de EC está ligado à "dinamização" da "cultura de consumo" e "estilos de vida alternativos", em que as "habilidades cognitivas e comunicacionais" são "fatores de produção". Envolve empresas que apropriam-se de "valores" ou "ideias-força" presentes na sociedade, segundo Albagli e Pires (2012, p. 119), e, posteriormente, os apresentam em forma de produtos e serviços. Aqui, se evidencia estreita associação com a ES que é espécie de economia criativa, que 
amplifica, por meio dos produtos ofertados, os valores da qualidade de vida, saúde, solidariedade, justiça social, entre outros. A ES também é valor humano e ideia-força, porém, não apropriada por terceiros. São valores e ideias vivenciadas no cotidiano por cada indivíduo envolvido no movimento e no fluxo da informação solidária.

Assim, foram apresentados alguns autores da área da CI que abordam de diferentes formas o tema da ES. A seguir, serão feitas algumas inter-relações entre o tema da ES e a Competência em Informação como forma de atuação do profissional da CI na ES.

\section{A competência informacional para o desenvolvimento econômico solidário}

A palavra competência tem muitos sentidos segundo o dicionário Houaiss (HOUAISS; VILLAR, 2001): significa a soma de conhecimentos e habilidades, em Psicologia a capacidade de resolver problemas, em Ciências Sociais, a capacidade objetiva das pessoas se aproximarem umas das outras. Todos os conceitos são pertinentes para a ES e para a Competência em Informação. Conhecimentos e habilidades são necessários, devem ser acessíveis, compartilhados, utilizados. Resolver problemas faz parte da dimensão técnica da Competência em Informação. Contudo, destaca-se o sentido de competência em Ciências Sociais. Aproximar as pessoas é, filosoficamente, a grande contribuição da ES e da Competência em Informação à sociedade, uma aproximação com respeito às diferenças, ética e harmoniosa. É por meio do consumo solidário que toda a sociedade se irmana.

Dentre as muitas abordagens possíveis, foi escolhida a Competência em Informação para orientar um caminho possível de apoio à ES. Mas qual o motivo da escolha? A informação solidária está fortemente associada à dimensão estética da Competência em Informação. A dimensão estética da Competência em Informação está ligada à "sensibilidade social", segundo Vitorino e Orello (2013, p. 5), que se "reflete na cidadania" e na "solidariedade", dimensão do uso da informação que faz florescer o respeito ao 
bem estar individual e coletivo. Além do mais, o bibliotecário é reconhecido por Dudziak (2007) como um "agente de transformação" que integra "ciência, tecnologia, desenvolvimento e inclusão social”.

A ES tem o potencial de incluir, por meio do consumo solidário de mercadorias oriundas dos EES e, ao subverter a lógica do capitalismo, essas mercadorias transfiguram-se em informação solidária pela expressão do consumidor. O contexto de consumo da mercadoria solidária, se explorado como informação e diferencial competitivo, podem contribuir grandemente com a ES. Sem embargo, o futuro da ES depende das instituições sociais, dos mediadores e do fortalecimento das relações de força em favor da sociedade ou do “ator popular" sustenta Gaiger (2004, p. 827).

A ação da ES passa, necessariamente, pela informação e conhecimento, e por meio desses vetores, os consumidores podem ser participantes ativos da ES. Especialmente, se observado que as pessoas estão se transfigurando em sujeitos informacionais "por excelência” segundo Mantovani e Moura (2012, p. 72-73), seres que mobilizam a si mesmos como informação por meio de seus processos pessoais, sociais e culturais. Nesse cenário, a Competência em Informação pode colaborar com a ES ao promover uma cultura de consumo inteligente, solidária e inclusiva, disseminar princípios éticos, estéticos, políticos e técnicos, ao longo da disseminação da informação de si.

Os EES e as instituições associadas são mediadores da informação solidária, todavia, as unidades de informação, destacadamente as bibliotecas, também podem ser entendidas como mediadores da informação no contexto solidário. Basta que os profissionais da informação despertem para a nova economia que se vizinha. A informação solidária abrange universo existente em arquivos, bibliotecas, periódicos científicos, relatos, história oral, entre outros. Tais informações devem estar ao alcance do MES, para que o fluxo da informação solidária siga como um grande rio. Arquivos inacessíveis, diretores de cooperativas que não se comunicam ou não dispõem a informação aos associados, bibliotecas públicas sem acervo sobre assuntos úteis ao bem estar popular, são travas que devem ser rompidas em benefício de todos, 
especialmente, em favor do elo mais fraco da sociedade e da economia. $\mathrm{Na}$ sociedade da informação e do conhecimento, a educação é determinante ao desenvolvimento econômico. Os ideais da educação na Sociedade do Conhecimento apresentam-se ligados aos ideais da Competência Informacional e da ES. Segundo Hargreaves (2004, p. 83), a educação "para além da economia do conhecimento" é orientada por "valores" e "cultiva" entre outras coisas, “comunidade", "inclusão", "simpatia", "democracia".

E o que é competência em informação? É conceito pouco explorado no Brasil (BORGES; SILVA, 2006), um processo de absorção de conceitos, atitudes e habilidades para lidar com a grande quantidade de informação (DUDZIAK, 2003) que avança sobre tudo e todos na pós-modernidade. Tem como objetivos formar pessoas que “[...] considerem as implicações de suas ações [...] observando aspectos éticos, políticos, sociais e econômicos." (DUDZIAK, 2003, p. 28-29). A Competência em Informação é um processo de aprendizagem permanente que liga a informação, o conhecimento e a inteligência de forma interdisciplinar, envolve valores sociais, pessoais, conhecimento e habilidades, em prol do desenvolvimento do pensamento crítico. (DUDZIAK, 2003).

As pesquisas atuais sobre Competência em Informação evidenciam sua importância para construir e manter as sociedades livres e democráticas; apontam a competência ligada à ação coletiva, mais do que individual (VITORINO; PIANTOLA, 2011). Vai além da soma de qualidades e habilidades, envolve conhecimentos e atitudes, é definida pelos olhos dos outros (DUDZIAK, 2007). Pode ser classificada em diferentes níveis: o nível da informação e da tecnologia que entende a competência como uma habilidade; o nível do conhecimento que entende a competência como reflexão; e o nível complexo que entende a competência como emancipação (DUDZIAK, 2007). A competência como emancipação liga-se de forma inconteste à ES:

Em seu sentido mais completo, a competência informacional surge como elemento chave ao desenvolvimento sustentável e, mais especificamente, à sustentabilidade social. O lócus das atividades de 
information literacy tende a se alterar do foco tecnológico funcionalista para o reconhecimento de uma preocupação que engloba o indivíduo como um todo (abordagem holística), incluindo os aspectos políticos, sociais e ambientais (DUDZIAK, 2007, p. 95).

Para superar as desigualdades sociais e econômicas, é necessário, segundo Dudziak (2007, p. 93), "empoderamento" da informação, que por sua vez, proporciona "autonomia" e "participação social". Para tanto, segundo a autora, é preciso entender os fatos científicos, políticos e tecnológicos, além dos valores que permitem construir consciência sobre si e sobre a realidade.

Desta forma, o Bibliotecário, ao desenvolver a Dimensão Estética da Competência Informacional em suas práticas diárias, estará cumprindo seu papel social de forma mais significativa, pois terá em seu fazer a sensibilidade e a solidariedade que em equilíbrio com as demais dimensões se refletem num fazer criativo, preocupado em atender as demandas sociais [...] desenvolver a Dimensão Estética da Competência proporciona aos indivíduos uma relação de solidariedade, em que a criatividade e a sensibilidade podem transformar-se em ação e responsabilidade social em seu fazer profissional (VITORINO; ORELO, 2013, p. 5).

A Competência em Informação caminha em direção à inclusão social, tal qual a ES. Em um nível superior, mais que o conjunto de qualidades, é um processo que leva à inclusão social; destaca o caráter social e educacional do bibliotecário, peça-chave do desenvolvimento socioeconômico e da sustentabilidade (DUDZIAK, 2007). Afinal, o exercício da cidadania está ligado à disseminação de informação de qualidade e aos fluxos de informação, à comunicação de debates críticos e abertos sobre assuntos que favoreçam a emergência de sociedade mais igual. Para tanto, as pessoas devem conseguir acessar, entender e utilizar a informação em benefício individual e coletivo (BORGES; SILVA, 2006).

A inclusão digital é um vetor importante no desenvolvimento da Competência em Informação. Estudo de Lucas e Martins (2009) mapeou as ações públicas federais relacionadas à inclusão digital, sob o olhar da Competência em Informação, inclusão digital, informacional e social. Segundo as autoras, existe "sinergia inerente" entre Competência em Informação e inclusão digital, o que reafirma o potencial da mesma ao exercício pleno da 
cidadania. Inclusão digital exprime acesso à informação digital, sua compreensão e processamento em conhecimento novo, vetor de qualidade de vida para as pessoas (SILVA et al., 2005, p. 30).

A Competência em Informação pode ser desenvolvida nas dimensões ética, técnica, política e estética. (VITORINO; PIANTOLA, 2011). As dimensões que mais se aproximam da ES são duas: ética e política. As demais também são de grande valor e são necessárias aos participantes da ES, conforme ilustra a Figura 2. Contudo, o consumo solidário (finalidade do fluxo da informação solidária) tem origem em uma reflexão ética e política: o consumo solidário é uma ação política. Observa-se que a Competência em Informação na ES se traduz, em um primeiro momento, em uma postura dos participantes de produzir, utilizar e compartilhar informação. Em um segundo momento, em competência da sociedade, que fomenta os EES por meio do consumo solidário. Os profissionais da informação emergem como mediadores entre a ES, a sociedade e a informação solidária, atores que facilitam e aceleram o fluxo da informação solidária.

Figura 2 - As dimensões da Competência Informacional na Economia Solidária.

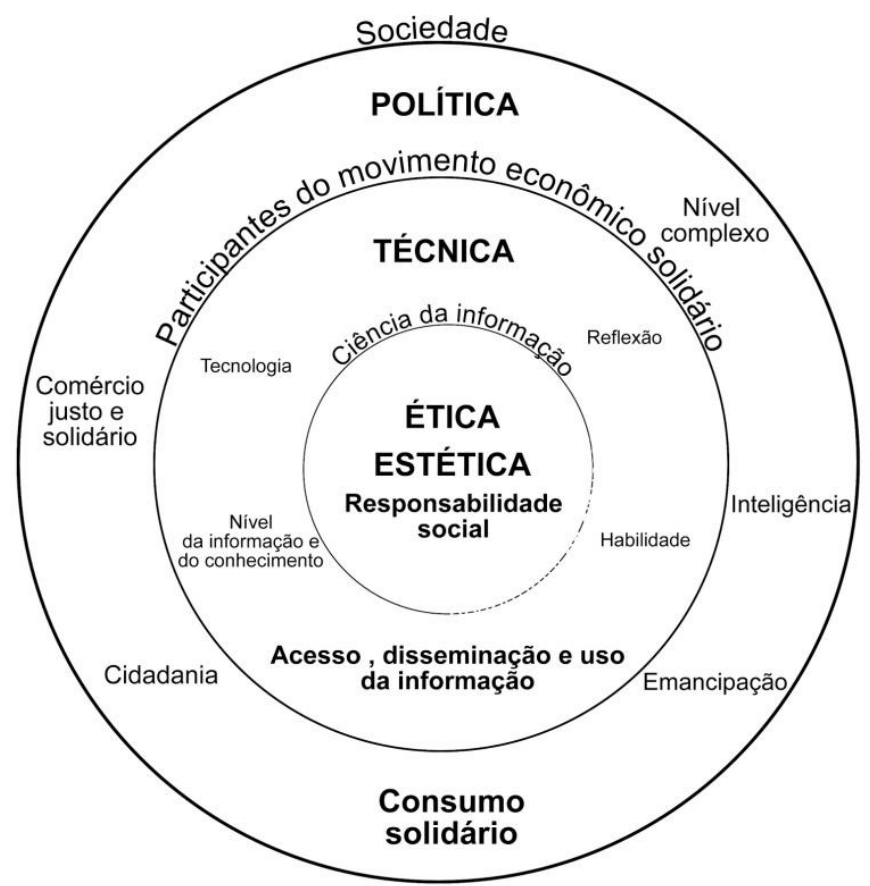

Fonte: Elaborada pelos autores. 
Todas as dimensões da Competência em Informação - ética, estética, política e técnica - acontecem naturalmente e em conjunto, fazem parte da personalidade das pessoas e da sociedade. Todavia, é a dimensão estética que aproxima, de forma efetiva, o profissional e as unidades de informação dos consumidores e da sociedade em geral (ORELO; CUNHA, 2013). A dimensão estética tem valor singular. Segundo Vitorino e Piantola (2011, p. 103), a "experiência estética" se faz atuante em "todos os aspectos da vida humana" e se constitui peça chave na "construção da subjetividade", é "determinante do próprio caráter do homem". Segundo as autoras, a dimensão estética está ligada à política e a ética, objetiva a "harmonia" social, é "movimento em direção à ordenação sensível do todo social".

Pode-se afirmar que a própria informação comporta uma dimensão estética, pois transmite-se aos indivíduos tanto a partir de referenciais do mundo exterior, com base em dados empíricos, verificáveis, objetivos, quanto do interior, por meio da intuição, da sensibilidade, da imaginação e da reflexão pessoal. Nesse sentido, ao dizermos que existe uma dimensão estética na competência informacional, referimo-nos à experiência interior, individual e única do sujeito ao lidar com os conteúdos de informação e a sua maneira de expressá-la e agir sobre ela no âmbito coletivo. (VITORINO; PIANTOLA, 2011, p. 103-104).

Oportunizar o acesso e o uso da informação é fundamental para criar oportunidades de crescimento social. No entanto, ainda são necessárias reflexões profundas acerca da responsabilidade social da CI (MELO; ARAÚJO, 2007), que contribuam com a aproximação dos profissionais da informação ao universo da ES, finalidade do presente estudo. A competência em informação é basilar em sociedades inclusivas e a CI como facilitadora da comunicação, informação e conhecimento, tem grande valor na redução das desigualdades por meio do conhecimento e da informação. (SILVA et al., 2005). Assim, fica evidente, no discurso da Competência em Informação, a forte ligação com a inclusão social e o exercício da cidadania, conceito que se harmoniza perfeitamente aos ideais da ES, de humanidade, ética e sustentabilidade. Trata-se, portanto, de alternativa de 


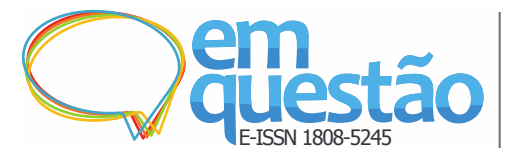

A economia solidária em Ciências da Informação: interrelações e atuações possíveis

Fabricio Foresti, Gregório Varvakis, Angel Freddy Godoy Viera e Elizete Vieira Vitorino

ação importante para atuação dirigida e mais intensa dos profissionais e pesquisadores da área de CI.

\section{Conclusões}

O estudo mostrou que a ES é uma tendência da economia contemporânea que promove o exercício da cidadania, o consumo solidário e a inclusão social. Para que a ES prospere é necessário, entre outros fatores, maior aproximação entre a sociedade e os EES. Os profissionais da informação tem a oportunidade de atuar como mediadores no processo de criação de competência (no sentido sociológico de aproximar as pessoas), por meio da gestão da informação solidária e do desenvolvimento da Competência em Informação em todas as dimensões, entre os membros do movimento da ES, usuários das unidades de informação, consumidores e sociedade em geral. Contudo, inicialmente, é necessário que os pesquisadores despertem para a temática.

Os objetivos do presente estudo foram alcançados ao mostrar como a temática da ES é abordada em CI. Claramente, aspectos políticos, sociais e ambientais, entre outros, ligam a CI de forma inconteste à ES. Em CI existem pesquisas importantes sobre temas correlatos à ES, como sustentabilidade, economia criativa e desenvolvimento sustentável, estudos com enfoque na informação e no conhecimento. Esses estudos podem avançar ainda mais em direção ao tema da ES, que ainda se mostra como novidade em CI e até o momento não atraiu o olhar dos pesquisadores da área.

Dentre os universos componentes da CI, a Competência em Informação mostrou, por meio dos artigos apresentados, de forma inconteste, estreita ligação com a ES, o que se evidencia nos valores éticos, sociais, humanos, de cidadania e autonomia. Trata-se de prática no âmbito das bibliotecas e instituições de ensino que pode transpor os muros das universidades e escolas para atuação social, econômica e política mais ampla. A Competência em Informação mostrase como ferramenta especial para a ES, ao promover a capacidade de selecionar, acessar, disseminar e produzir informação para o bem comum, orientada ao 
comércio e consumo solidário e justo, em conformidade com os ideais e objetivos da ES.

Acredita-se que a principal contribuição do estudo foi aproximar a ES e a CI e, assim, abrir caminhos para pesquisas futuras. Muitas pesquisas são necessárias e muitos eventos acontecem em todo Brasil e no exterior. Pesquisas que explorem métodos qualitativos e quantitativos, pesquisas de campo, estudos de caso com cooperativas e EES, que auxiliem na compreensão precisa dos fluxos da informação solidária, das necessidades de informação dos EES e, também, das necessidades da sociedade perante os MES, com vistas ao diálogo social e desenvolvimento da Competência em Informação de forma transversal, se mostram importantes.

Além disso, é importante que o olhar do profissional que atua no cotidiano em bibliotecas e demais unidades de informação desperte para atender a comunidade solidária e, igualmente, que as unidades de informação se tornem vetores do fluxo da informação solidária, que fomentem o consumo solidário, ético e sustentável. Eis uma forma do profissional da informação exercer sua famigerada responsabilidade social. Ações simples com grande poder de mudança e colaboração podem ser realizadas de muitas formas, seja por meio da disseminação seletiva da informação de qualidade e relevante, da gestão de documentos eficaz nos arquivos dos EES, da gestão do conhecimento, dos livros e da leitura, da simples cessão do espaço e chamamentos para atrair a ES para dentro das bibliotecas. Talvez as bibliotecas públicas possam tornar-se centros de referência em informação solidária.

Estará ao alcance dos profissionais e das unidades de informação atuar com um movimento tão importante para o Brasil quanto o MES? É fundamental ao profissional da informação o reconhecimento de si e da profissão como instrumentos de mudança social, visto que somente assim pode acontecer efetiva colaboração, para que, finalmente, as portas das unidades de informação se abram à ES e se transformem em verdadeiras unidades de informação solidárias. 


\section{Referências}

ALBAGLI, Sarita. A nova centralidade do imaterial e o desafio do desenvolvimento sustentável. Revista Brasileira de Biblioteconomia e Documentação, São Paulo, v. 5, n. 1, p. 104-116, jan./abr. 2009.

ALBAGLI, Sarita; PIRES, Vladimir Sibylla. Estratégias empresariais, dinâmicas informacionais e identidade de marca na economia criativa. Perspectivas em Ciência da Informação, Belo Horizonte, v. 17, n. 2, p. 109122, 2012.

ANDION, Carolina. A gestão no campo da economia solidária: particularidades e desafios. Revista de Administração Contemporânea, Curitiba, v. 9, n. 1, mar. 2005.

BORGES, Jussara; SILVA, Helena Pereira da. Democracia eletrônica e competência informacional. Informação \& Sociedade, João Pessoa, v. 16, n. 1, p. 129-137, 2006.

BRASIL. Ministério do trabalho e emprego. Portaria n. 2.060 de 30 de dez. de 2014. Diário Oficial [da] República Federativa do Brasil, Brasília, 8 de jan. de 2015.

BRASIL. Ministério do trabalho e emprego. Portal do trabalho e emprego. [Brasília, 2014a].

BRASIL. Ministério do Trabalho e Emprego. Sistema de Informações em Economia Solidária. O que é o SIES? [Brasília, 2014b].

COOPERATIVAS DE LAS AMÉRICAS. Región de Alianza Cooperativa Internacional. Estatísticas cooperativas. c2015.

CENTRO DE ESTUDOS e Pesquisas em Economia Pública e Social. Seção Brasil. Campinas, [2017].

CIRANDAS: a rede social econômica da Economia Solidária. [2014].

DEMO, Pedro. Ambivalências da Sociedade da Informação. Ciência da Informação, Brasília, v. 29, n. 2, p. 37-42, maio/ago. 2000.

DUDZIAK, Elisabeth Adriana. Information literacy: princípios, filosofia e prática. Ciência da Informação, Brasília, v.32, n.1, p.23-35, jan./abr. 2003.

DUDZIAK, Elisabeth Adriana. O bibliotecário como agente de transformação em uma sociedade complexa: integração entre ciência, tecnologia, desenvolvimento e inclusão social. Ponto de Acesso, Salvador, v. 1, n. 1, p. 8898, jan./jun. 2007. 
DURIGAN, Gisele Mara; MORENO, Nádina Aparecida. O fluxo e a demanda de informação: a busca pelo ponto de equilíbrio na sociedade da informação.

Ponto de Acesso, Salvador, v. 7, n. 2, 2013.

FONSECA, Reuber da Silva; MACHADO, Lucília Regina de Souza. Representações de empreendimentos econômicos solidários sobre a Internet. Transinformação, Campinas, v. 23, n. 3, p. 195-206, 2011.

FÓRUM BRASILEIRO DE ECONOMIA SOLIDÁRIA. 2014.

FRANÇA FILHO, Genauto Carvalho de. A problemática da economia solidária: um novo modo de gestão pública? Cadernos EBAPE.BR, Rio de Janeiro, v. 2, n. 1, mar. 2004.

FREIRE, Isa Maria. Sobre a temática "responsabilidade social" na literatura da ciência da informação indexada pela brapci. Logeion: filosofia da informação, v. 1, n. 1, p. 59-76, 2014.

FURNIVAL, Ariadne Chloë. Desenvolvimento sustentável e a sociedade da informação: uma parceria natural? Transinformação, Campinas, v. 12, n. 1, p. 73-82, jan./jun. 2000.

GAIGER, Luiz Inácio Germany. A economia solidária e o projeto de outra mundialização. Dados, Rio de Janeiro, v. 47, n. 4, 2004.

GODOY VIERA, Angel Freddy ; FORESTI, Fabricio. Informação e conhecimento na Economia Solidária. Biblios, n. 62, 2016.

HARGREAVES, Andy. O ensino na sociedade do conhecimento: educação na era da insegurança. Porto Alegre: Artmed, 2004. 237 p.

HOUAISS, Antônio; VILLAR, Mauro de Salles. Competência. In: HOUAISS, Antônio; VILLAR, Mauro de Salles. Dicionário Houaiss da Língua

Portuguesa. Rio de Janeiro: Objetiva, 2001. p. 775

INTERNATIONAL CO-OPERATIVE ALLIANCE. Aims and goals. Brussels, 2015.

KUYVEN, Patricia Sorgatto; KAPPES, Sylvio Antônio. II Mapeamento da Economia Solidária Região Sul, Resultados do segundo Mapeamento Nacional. Coordenação: Luiz Inácio Gaiger. São Leopoldo, Brasil, 2013.

LUCAS, Elaine Rosangela de Oliveira; MARTINS, Taliana da Silva. Os programas de inclusão digital do Governo Federal sob a óptica da competência informacional. Liinc em revista, Rio de Janeiro, v. 5, n. 1, p. 82-99, mar. 2009.

MELO, Ana Virginia Chaves de; ARAÚJO, Eliany Alvarenga de. Competência informacional e gestão do conhecimento: uma relação necessária no contexto da 
sociedade da informação. Perspectivas em Ciência da Informação, Belo Horizonte, v. 12, n. 2, p. 185-201, maio/ago. 2007.

MANTOVANI, Camila Maciel Campolina Alves; MOURA, Maria Aparecida. Informação, interação e mobilidade. Informação e Informação, Londrina, v. 17, n. 2, p. 55-76, maio/ago. 2012.

ORELO, Eliane Rodrigues Mota; CUNHA, Miriam Figueiredo Vieira da. O bibliotecário e a competência informacional. Informação \& Sociedade:

Estudos, João Pessoa, v. 23, n. 1, 2013.

PERES, Mônica Regina. Competência informacional: educação e sociedade. Revista Ibero-Americana de Ciência da Informação, v. 4, n. 1, 2011.

SILVA, Helena Pereira da et al., Inclusão digital e educação para a competência informacional: uma questão de ética e cidadania. Ciência da Informação, Brasília, v. 34, n. 1, p. 28-36, jan./abr. 2005.

SINGER, Paul. Economia solidária versus economia capitalista. Sociedade e Estado, Brasília/DF, v.16, n. 1-2, p. 100-112, 2001.

SINGER, Paul. Desenvolvimento capitalista e desenvolvimento solidário. Estudos Avançados, São Paulo, v. 18, n. 51, p. 7-22, 2004.

SUGAHARA, Cibele Roberta; VERGUEIRO, Waldomiro de Castro Santos. Fluxo de informação na perspectiva do ambiente em rede. Revista Digital de Biblioteconomia \& Ciência da Informação, Campinas, v. 11, n. 2, 2013.

VITORINO, Elizete Vieira; PIANTOLA, Daniela. Dimensões da Competência Informacional. Ciência da Informação, Brasília, v. 40, n. 1, p. 99-110, jan./abr. 2011.

VITORINO, Elizete Vieira; ORELO, Eliane Rodrigues Mota. A dimensão estética da competência informacional. In: ENCONTRO NACIONAL DE PESQUISA EM CIÊNCIA DA INFORMAÇÃO, 14., Florianópolis. Anais... Florianópolis, 2013. Pôster apresentado no GT 6: Informação, Educação e Trabalho.

\section{The Solidarity Economy in Information Science: possible interrelationships and actions}

\footnotetext{
Abstract: Solidary Economy is an alternative form of production and consumption that aims to reduce social inequalities. It is an international movement related to other contemporary themes such as sustainability.
} 
Therefore, this exploratory bibliographical research aims at verifying how the theme of the Solidary Economy emerges in Information Science and exploring common points between information literacy and Solidary Economy. The results show that Solidarity Economy is still a novelty in Information Science; however, other related topics present a considerable amount of scientific production, which explores the potential of information in the economicsustainable context, and clarifies the convergence between information literacy and Solidarity Economy. The conclusion is that information professionals can act in many ways in the Solidarity Economy area, especially by developing information competence and producing more scientific researches about the subject.

Keywords: Information Science. Solidarity economy. Information literacy.

Recebido: $14 / 07 / 2017$

Aceito: $13 / 11 / 2017$

\footnotetext{
${ }^{1}$ Por exemplo, o evento realizado em Nova York, em 2015, na Sede das Nações Unidas, onde ocorreu o Fórum Internacional de Economia Social e Solidária, em que empresários se reuniram para organizar evento paralelo em parceria com Instituto de Investigação das Nações Unidas para o Desenvolvimento Social (UNRISD) e com o Serviço de Ligação das Nações Unidas com Organizações Não Governamentais (UN-NGLS), com apoio dos governos da França, Equador e Marrocos, sobre o tema da "Economia Social e Solidária: alterar as relações econômicas para a equidade e desenvolvimento sustentável na agenda pós-2015". Ver também a Conferência Nacional de Economia Solidária, cuja terceira edição ocorreu em 2014, em Brasília.
} 